LITERATURE REVIEW

\title{
Juvenile nasopharyngeal angiofibroma - literature review and case series
}

\author{
Alexis Vuzitas ${ }^{1}$, Claudiu Manea ${ }^{1,2,3}$ \\ ${ }^{1}$ ENT\&HNS Department, "Sfanta Maria" Hospital, Bucharest, Romania \\ ${ }^{2}$ CESITO Center, "Sfanta Maria” Hospital, Bucharest, Romania \\ 3"Carol Davila" University of Medicine and Pharmacy, Bucharest, Romania
}

\begin{abstract}
Juvenile nasopharyngeal angiofibroma is a rare benign tumour of vascular origin found in adolescent males, originating around the sphenopalatine foramen. Although the exact pathogenesis of the tumour is not yet known, natural history and growth patterns can be predicted. JNA progressively involves the nasopharynx, nasal cavity, paranasal sinuses, pterygopalatine fossa, infratemporal fossa and, in severe cases, an orbital or intracranial extension can be seen. Early diagnosis based on clinical examination and imaging is mandatory to ensure the best resectability of the tumour, as small to moderate tumours can be managed exclusively endoscopically. Preoperative angiography can reveal the vascular sources and allow embolization to prevent significant bleeding. We present a brief literature review followed by our case series of endoscopic removal of 7 juvenile nasopharyngeal angiofibromas.
\end{abstract}

KEYWORDS: juvenile nasopharyngeal angiofibroma, JNA, endoscopic surgery.

\section{INTRODUCTION}

Juvenile nasopharyngeal angiofibroma (JNA) is a rare vascular tumour affecting mostly adolescent males, benign by histopathology, but considered 'malignant' by location, local invasion tendency and possibility of recurrence.

\section{CLINICAL DIAGNOSIS}

JNA typically affects adolescent males, although cases in females and older patients have been described. Early symptoms include bleeding manifested as either repeated epistaxis or blood-stained sputum, unilateral nasal obstruction, ear fullness due to serous otitis media. As the mass expands, depending on the size and structures involved, the patient may present headaches, nasal discharge, anosmia, rhinolalia, swelling/deforming of the cheek/palate, epiphora, proptosis and/or decreased visual acuity (when the orbit is breached), trismus (when the infratemporal fossa is involved) $)^{1,2}$.
Anterior rhinoscopy and endoscopic visualization show a smooth, rubbery, possibly lobulated, polypoid, yellowish to red/purple, hypervascularized mass arising from behind the middle turbinate (which can be laterally displaced), with variable size, extension and choanal obstruction ${ }^{1-3}$. Because the tumour has mainly submucosal growth, it may create the false appearance of origin in the middle turbinate. JNA commonly presents contact bleeding, and mild pulsations may be seen on endoscopic examination (Figures 1, 2 and 3).

Oral cavity examination may show an inferior displacement of the soft palate by the nasopharyngeal mass, and intraoral palpation may reveal a mass between the maxilla and the ascending ramus of the mandible. Bloodstains on the posterior pharyngeal wall may be seen.

\section{ETIOLOGY / PATHOGENESIS}

No consensus is yet reached on the etiology of JNA, but recent reports emphasise similarities with either a hamartoma or haemangioma/vascular malformation with developmental origin. Immunostaining of vari- 


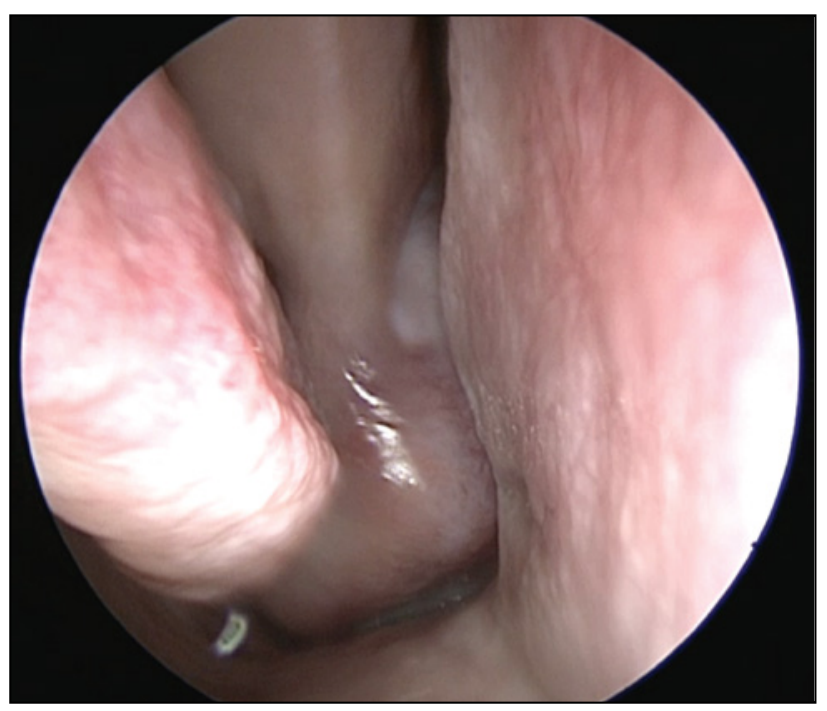

Figure 1 Right-sided nasal endoscopy: a smooth mass originating from behind the middle turbinate with near-total obstruction of the right nostril.

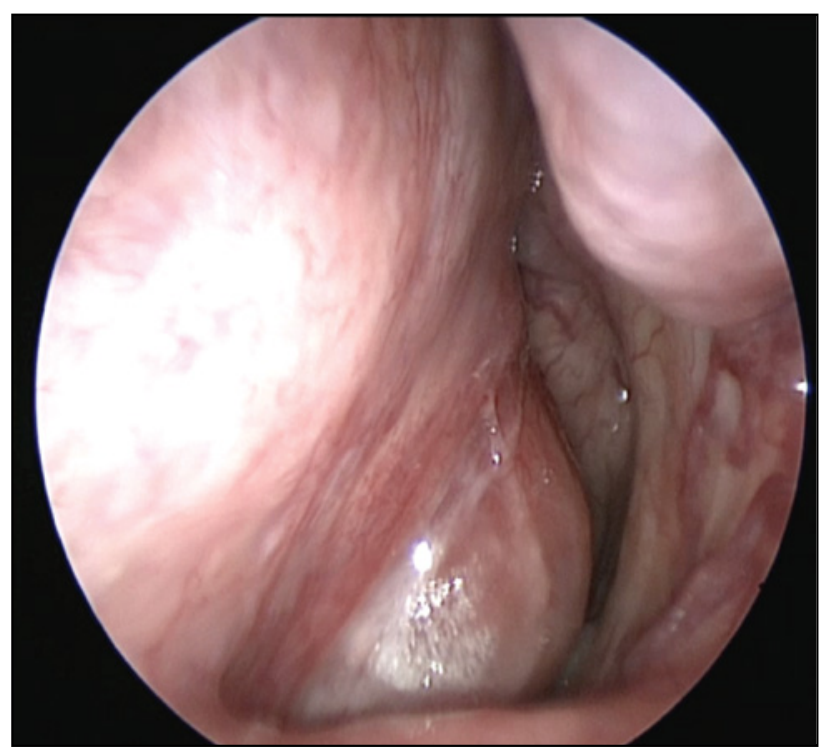

Figure 3 Contralateral nostril endoscopy sows the JNA occupying the rhinopharynx and deforming the posterior nasal septum.

ous components in the stromal and endothelial components of JNA suggests that JNA is an angiogenic histogenetic tumor which opens the path to a possible antiangiogenetic therapy. Simultaneous growth of the 2 main components (vascular and fibrous) in JNAs suggests a vascular hamartoma/ pathologic angiogenesis $^{46}$. Because the maxillary artery (the only remnant of the first pharyngeal arch artery) is the main vascular source for JNAs, the embryological origin of incomplete first pharyngeal arch artery was theorised. Secondary blood supply from the internal carotid artery suggests an early developmental connection between the internal and external carotid systems ${ }^{7}$. Androgen receptor expression in both the stromal and vascular

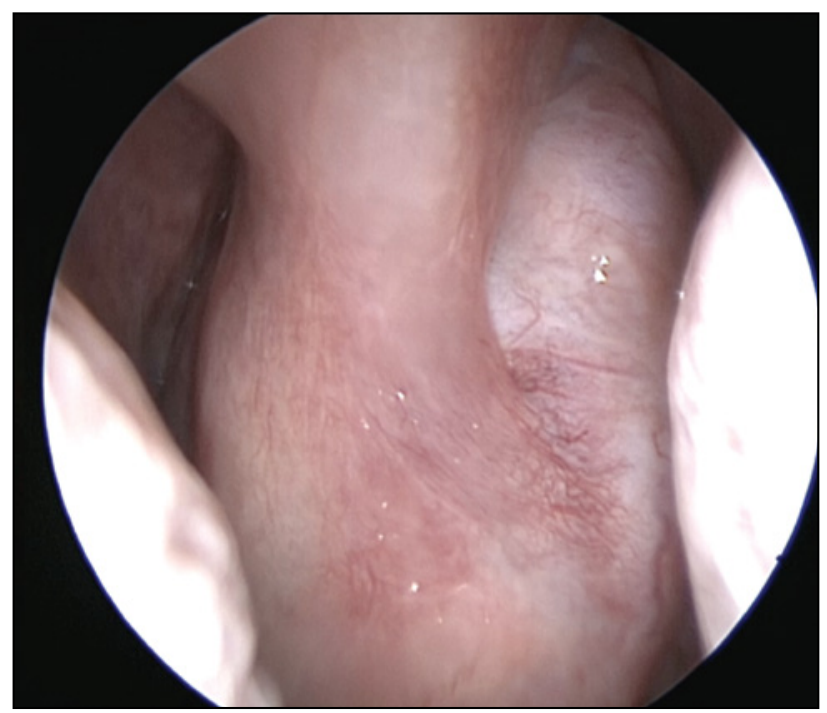

Figure 2 Close-up of the tumour shows the difficulty in identifying the correct margins from the middle turbinate due to the submucosal growth of JNA.

components has led to the idea that JNAs have endocrinologic origin; however, no endocrinologic pathology was identified in patients with JNA ${ }^{8,9}$.

\section{HISTOLOGY}

Microscopic evaluation of JNA specimens reveals a loose fibrovascular stroma with abundant and heterogeneous capillaries. Cellularity includes various densities of myofibroblasts with pleomorphic or multiple nuclei, endothelial cells and variable smooth muscle without the ability to perform proper vasoconstriction (contributing to JNAs bleeding predisposition). Mitotic activity and inflammation are usually minimal ${ }^{3,10-12}$.

\section{IMAGING}

Plain radiographs are no longer in use for the diagnostic algorithm of JNA.

CT scan reveals a lobulated, heterodense, non-encapsulated soft tissue density mass of various sizes centred on the sphenopalatine foramen. At the time of diagnosis, JNA usually involves the nasopharynx and the pterygopalatine fossa, producing widening of the sphenopalatine foramen and anterior bowing of the posterior maxillary sinus wall (Holman-Miller sign, considered pathognomonic by some). JNA expands mainly through predetermined minimal resistance pathways and less through bone remodelling and resorption, and in advanced cases the tumour can involve the sphenoid, maxillary or ethmoid sinuses, the nasal fossa, the infratemporal fossa, the orbit, the skull base. The important contrast enhancement confirms the abundant vascularity ${ }^{13-15}$ (Figures 4 and 5). 


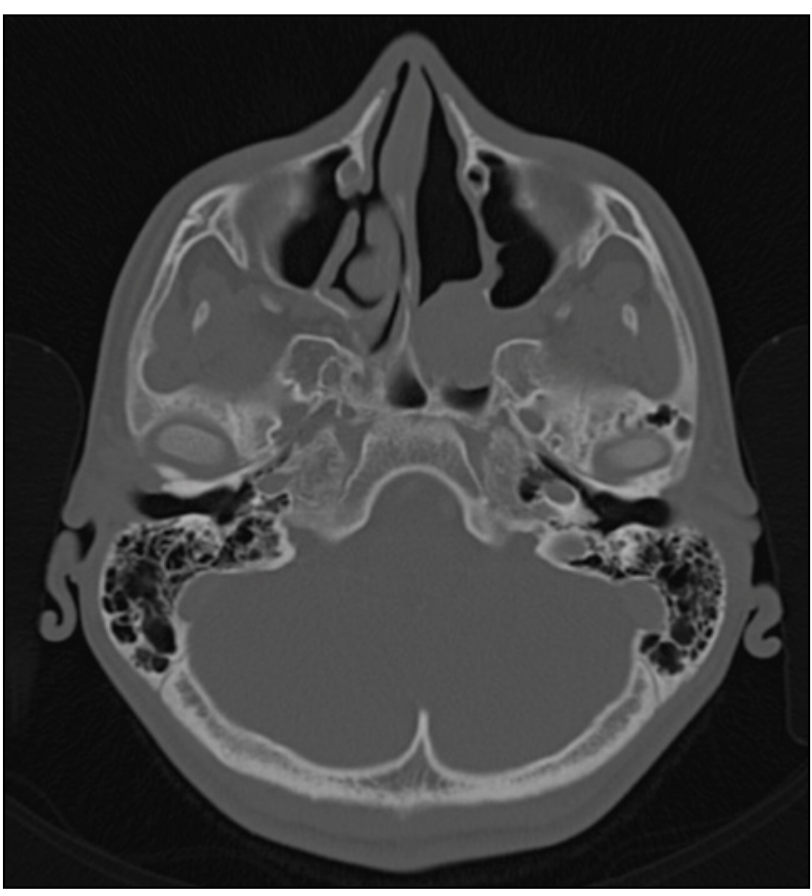

Figure 4 Cranio-facial CT scan of a 16-year-old male showing small left sided JNA originating around the sphenopalatine foramen.

MRI scan is less precise in identifying osseous changes and landmarks but is invaluable when the angiofibroma has breached into the soft tissues beyond the skull base or orbital walls. MRI signal is usually heterogeneous, with numerous flow (signal) voids due to the abundance of blood vessels contributing to the

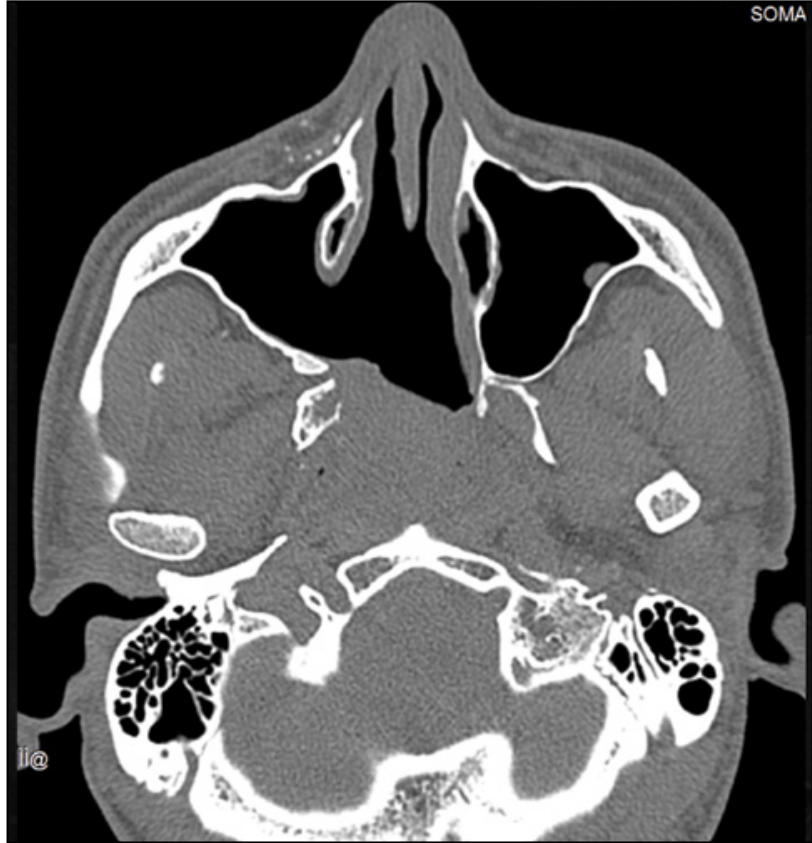

Figure 5 Cranio-facial CT scan of a JNA recurrence in the nasopharynx. The posterior nasal septum and part of the lateral nasal wall were resected during initial surgery while sparing the nasolacrimal duct.

characteristic salt and pepper appearance. On T1 weighted sequences JNA produces intermediate signal comparable to the muscle and on $\mathrm{T} 2$ weighted sequences it emits intermediate to hyperintense signal. Enhancement after intravenous contrast injection is present in all cases $^{13,16}$ (Figures 6, 7 and 8).
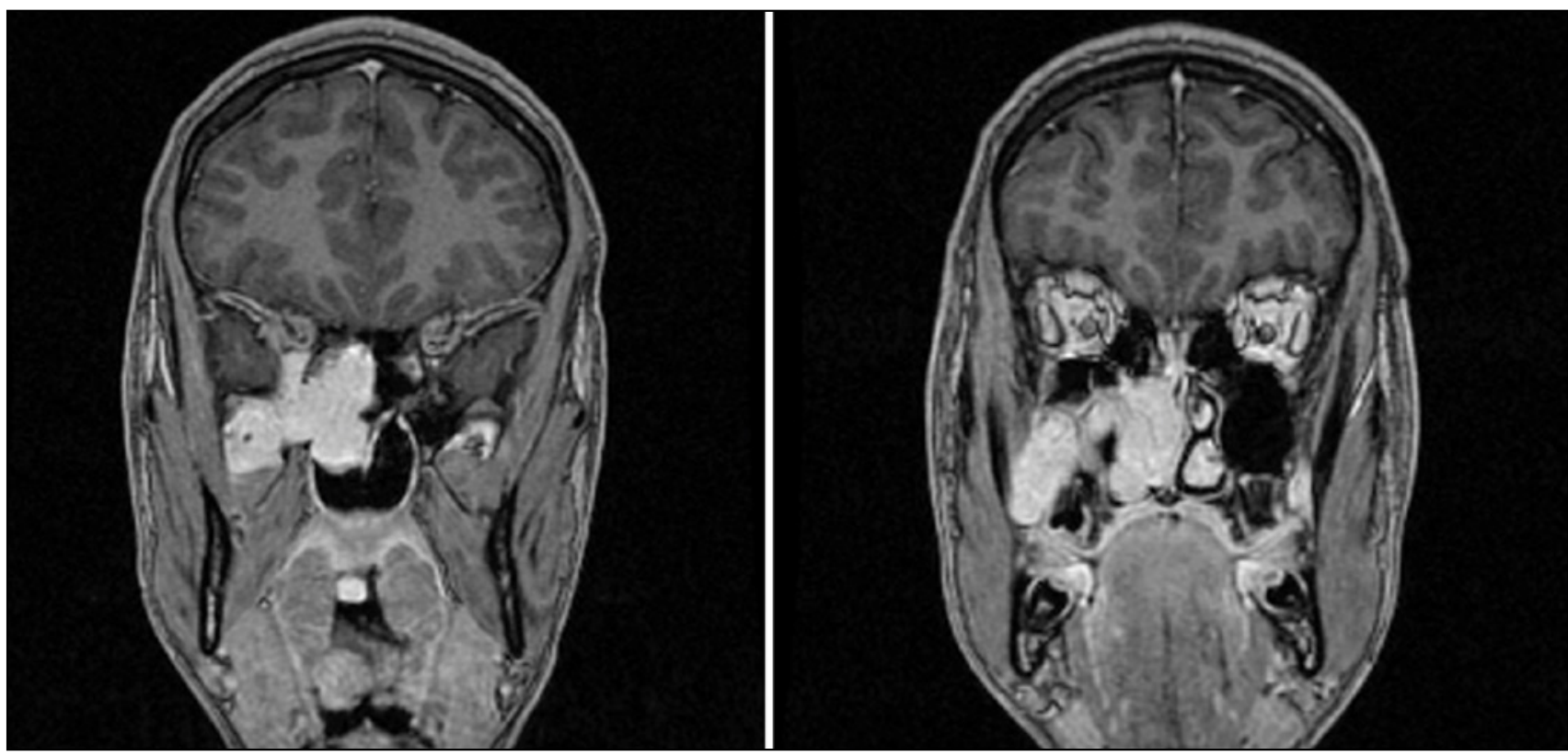

Figure 6 Two coronal head MRI slices of a patient with JNA. The typical growth patterns towards the nasopharynx, sphenoid sinus, orbital apex, pterygopalatine fossa, infratemporal fossa can be seen. This is mainly done by enlarging pre-existent communications between these regions. 


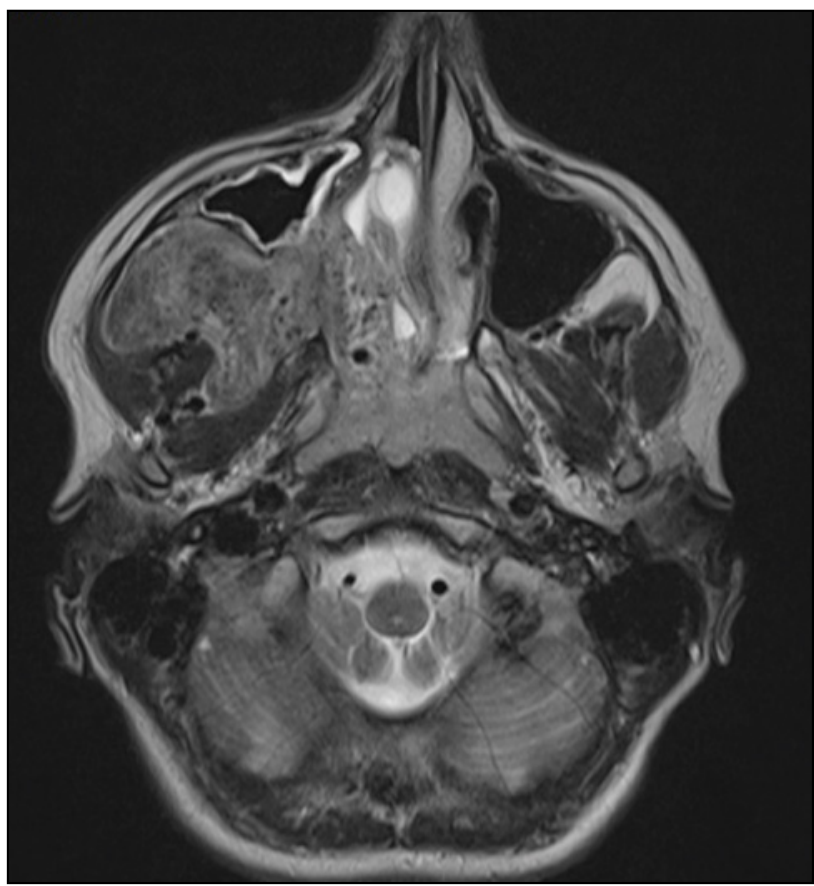

Figure 7 Axial head MRI slice of a large JNA. The tumour was causing facial deformity and was palpable in the zygomatic area at this stage. The right maxillary sinus was gradually reduced in volume due to extrinsic compression.

\section{ANGIOGRAPHY AND EMBOLIZATION}

Angiography identifies the main feeding vessels of the tumour which usually include the distal maxillary artery, the ascending pharyngeal artery, the ascending and descending palatine arteries, the sphenopalatine artery, the posterior superior alveolar branches and, less commonly, the pterygoid canal (vidian) artery, the ophthalmic artery, the sphenoid branches ${ }^{2,13,15,17}$. Bilateral supply is possible in JNAs and some authors recommend preoperative bilateral carotid systems angiography ${ }^{18}$. Angiography is of less importance as a diagnostic tool and more as a surgical treatment adjuvant via the possibility of embolization. Most surgeons seem to prefer a preoperative embolization of the tumour but no consensus is reached as embolization is not mandatory. Embolization may not be as effective in reducing intraoperative bleeding and may be justified only in larger tumours when shrinkage ensures superior resectability. Furthermore, tissue shrinkage due to embolization may impede the correct identification of surgical margins thus increasing recurrence rates ${ }^{19-22}$. Direct tumoral puncture embolization is also a feasible alternative to the traditional route via angiography $^{23}$ (Figure 9).

The characteristic appearance on imaging studies together with the significant risk of bleeding has determined the sampling of a biopsy specimen both unrequired and not recommended. Histopathologic examination is performed on the en bloc surgical excision specimen.

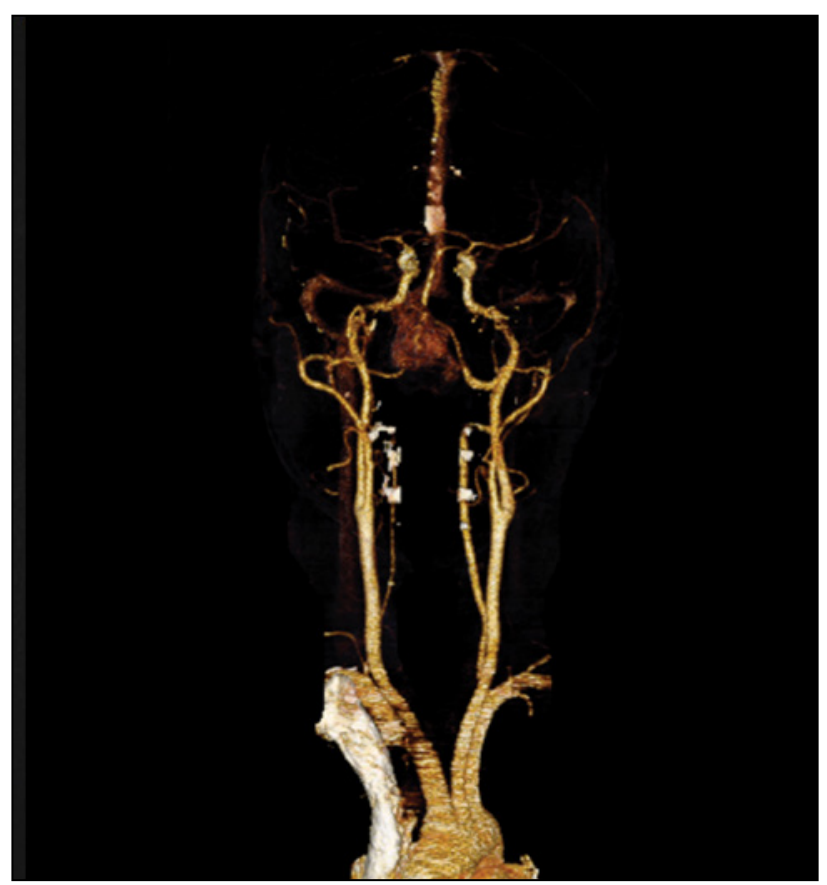

Figure 8 Bilateral vascularization of a JNA as seen on angio-MRI.

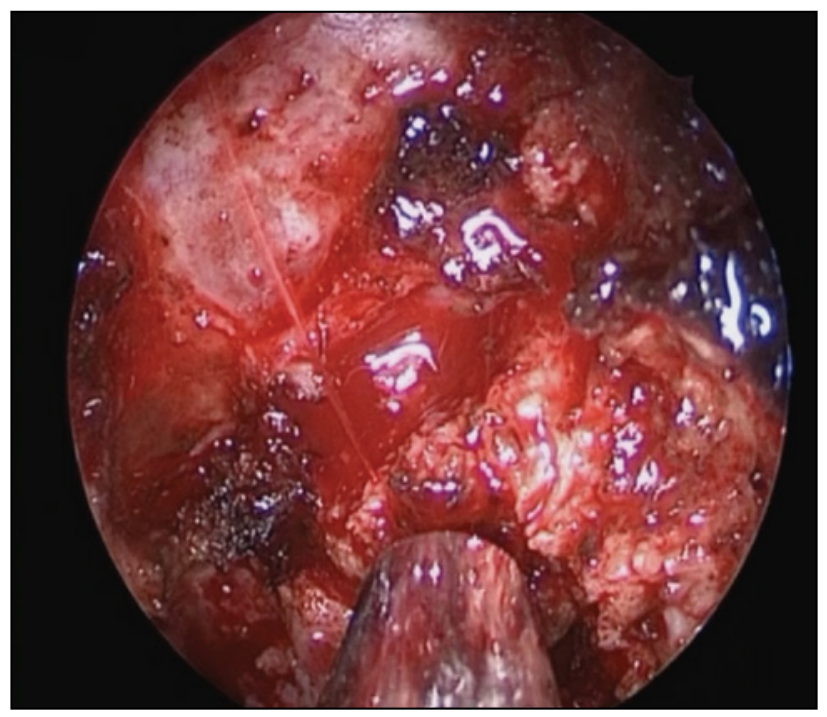

Figure 9 Arterial bleeding encountered in a JNA case when resecting along the vidian canal. Even in patients who received preoperative embolization, a blood-free surgical field may not be obtained because of collaterals and variable origin of the vidian artery from either the internal or external carotid systems.

\section{NATURAL HISTORY AND GROWTH PAT- TERNS}

JNA growth follows the principle of least resistance, and spreads through fossae, foramina, fissures earlier than it produces bone erosion. Some typical spread patterns include $e^{1,24}$ :

1. Through the sphenopalatine foramen $\rightarrow$ nasal cavity, nasopharynx

2. Through the vidian canal $\rightarrow$ sphenoid sinus 
3. Through the superior and inferior orbital fissures $\rightarrow$ orbit, cavernous sinus, intracranially

4. Through the maxillary nerve canal $\rightarrow$ parasellar region, intracranially

5. Through the pterygomaxillary fissure $\rightarrow$ infratemporal fossa, cheek

6. Sinus walls erosion $\rightarrow$ maxillary, ethmoid, sphenoid sinuses

7. By erosion of the pterygoid process, greater wing of the sphenoid bone and middle cranial fossa floor $\rightarrow$ intracranially.

\section{STAGING SYSTEMS}

JNA staging is based on local growth and involvement of adjacent structures seen on imaging (CT and/or MRI). Staging can help in choosing a surgical approach although no consensus is reached by all surgeons. Some of the more commonly used classification systems are Fisch ${ }^{25}$ and Radkowski ${ }^{26}$, seen below (Tables 1 and 2).

Table 1

Fisch classification ${ }^{25}$

\begin{tabular}{cc}
\hline Fisch classification & Description \\
\hline Type 1 & Tumour limited to the nasopharynx; limited or negligible bone erosion of the sphenopalatine foramen \\
\hline Type 2 & Tumour invading the pterygopalatine fossa or the maxillary, ethmoid or sphenoid sinus with bone destruction \\
\hline Type 3a & Tumour invading the infratemporal fossa or orbit without intracranial involvement \\
\hline Type 3b & Tumour invading the infratemporal fossa or orbit with intracranial parasellar extradural involvement \\
\hline Type 4a & Intracranial intradural tumour without involvement of the cavernous sinus, pituitary fossa or optic chiasm \\
\hline Type 4b & Intracranial intradural tumour with involvement of the cavernous sinus, pituitary fossa or optic chiasm \\
\hline
\end{tabular}

Table 2

Radkowski classification ${ }^{26}$

\begin{tabular}{cc}
\hline Radkowski classification & Description \\
\hline Type $1 \mathrm{a}$ & Tumour limited to the nose and nasopharynx \\
\hline Type $1 \mathrm{~b}$ & Tunour extension to one or more paranasal sinuses \\
\hline Type $2 \mathrm{a}$ & Minimal extension to the pterygopalatine fossa \\
\hline Type $2 \mathrm{~b}$ & Tumour occupying the pterygopalatine fossa without orbital involvement \\
\hline Type $2 \mathrm{c}$ & Infratemporal fossa extension without cheek or pterygoid plate involvement \\
\hline Type $3 \mathrm{a}$ & Skull base erosion (middle cranial fossa or pterygoids) \\
\hline Type $3 \mathrm{~b}$ & Intracranial extension with or without cavernous involvement \\
\hline
\end{tabular}

\section{TREATMENT}

Surgical excision is considered the frontline treatment of JNA. The approach is based on tumour extension at the time of surgery, classifications, surgeon experience, facility equipment, patient acceptance ${ }^{27}$.

\section{Endoscopic approach}

Endoscopic approach is a safe and effective surgical approach to JNA. Progress in equipment means endoscopic surgeons can tackle progressively larger and more invasive lesions, such as some Radkowski type IIIa tumours or involving the orbit, the infratemporal fossa and the parasellar region, which are no longer considered absolute contraindications ${ }^{1,28}$. An endoscopic approach is preferable to open surgery because it ensures a better visualisation of the tumour margins, which translates to a more accurate dissection, less bleeding, less frequently requiring transfusion; other advantages include a shorter duration of surgery, smaller impact on craniofacial growth, no aesthetic defect and fewer complications ${ }^{29}$. En-bloc resection can be obtained by dissecting posteriorly in a submucosal and subperiosteal plane until transoral removal of the tumour; some authors recommend keeping the tumour enveloped in a vasoconstrictor soaked gauze and gradually exposing it to work in a bloodless field ${ }^{30}$. Partial or complete removal of normal structures such 
as the turbinates, lateral nasal wall, posterior maxillary sinus wall, nasal septum is usually necessary to completely visualise and approach the tumour. Some surgeons prefer a four-hand approach and start the operation by creating a septal window to allow passage of 1 or 2 instruments from the unaffected side ${ }^{31}$. Shorter postoperative hospitalisation periods are usually required for exclusively endoscopic surgery.

\section{Open approach}

Open approaches include lateral rhinotomy approach with its variations, transfacial approach, midfacial degloving, transpalatal approach, Le Fort transmaxillary osteotomies, infratemporal fossa approach. Combined endoscopic and open approaches have also been used in selected cases. Two-step procedures may sometimes be required for the extracranial and intracranial components of the tumour.

\section{Radiotherapy}

Low-dose (30-36 Gy) radiotherapy may be an alternative for large, unresectable tumours and recurrences with good local control rates and acceptable short-term morbidity ${ }^{32}$. Long-term effects such as radiation-induced malignancy should be taken into account since JNA affects predominantly young people. Osteoradionecrosis, secondary cataract and growth restriction have also been reported ${ }^{1}$. Gamma knife radiosurgery is another form of radiotherapy which can successfully produce lesion regression in invasive, residual or recurrent disease unamendable to surgery - such as some orbital or cavernous sinus involvement ${ }^{33,34}$.

Spontaneous regression and even near-total disappearance of JNAs has been described in few cases, especially in older patients and recurrences, and it has been theorised that hormonal changes after adolescence may contribute to the potentially androgen dependent tumour involution ${ }^{35,36}$.

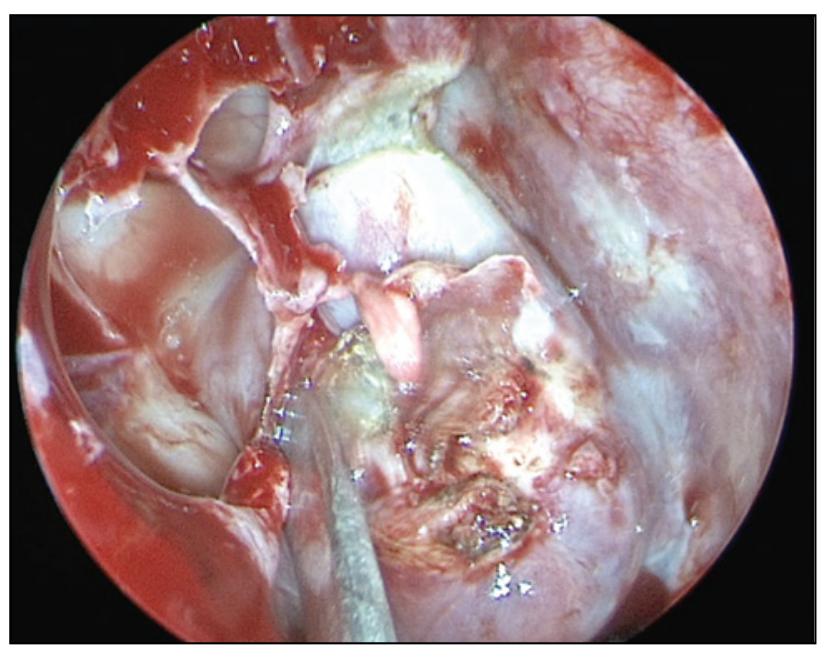

Figure 10 Submucosal dissection of the tumour from the lateral nasal wall. A large antrostomy is seen. The right middle turbinate was resected beforehand.

\section{OUR SERIES}

We conducted a 3-year retrospective study on patients diagnosed with JNA in the ENT\&HNS Department of "Sfanta Maria" Clinical Hospital in Bucharest. These 8 patients were males with ages ranging from 13 to 27 years (average 21 years). The cardinal symptom was nasal obstruction (present in all cases); epistaxis was the main complaint in 3 cases that received nasal packing or cauterization prior to admission, and, upon taking a thorough history, 2 more patients mentioned minor recurrent epistaxis and blood-stained sputum. One case presented with facial deformity due to important infratemporal fossa and cheek involvement.

Radkowski staging ranged from Ia to IIc with large zygomatic and infratemporal fossa involvement. No patient had intracranial extension.

7 patients had no prior surgery while 1 patient had initially a subtotal resection and returned after 4 years with nasopharyngeal and sphenoid sinus recurrence of JNA. The 7 new cases underwent preoperative embolization, while the recurrence was managed without another angiography and embolization.

Exclusively endoscopic resection was performed in 7 out of 8 patients. One patient with large infratemporal fossa and cheek involvement could not receive surgical treatment at the time of admission due to difficulty in assembling the multidisciplinary team required to safely perform the operation.

The endoscopic surgical technique involved submucosal dissection of the JNA with prior removal of part of the lateral nasal wall including the middle and inferior turbinate if needed, anterior and posterior ethmoidectomy, resection of the posterior third of the nasal septum. Alternating single-surgeon and 3 to 4 -hand technique were used (Figures 10 to 14$)$.

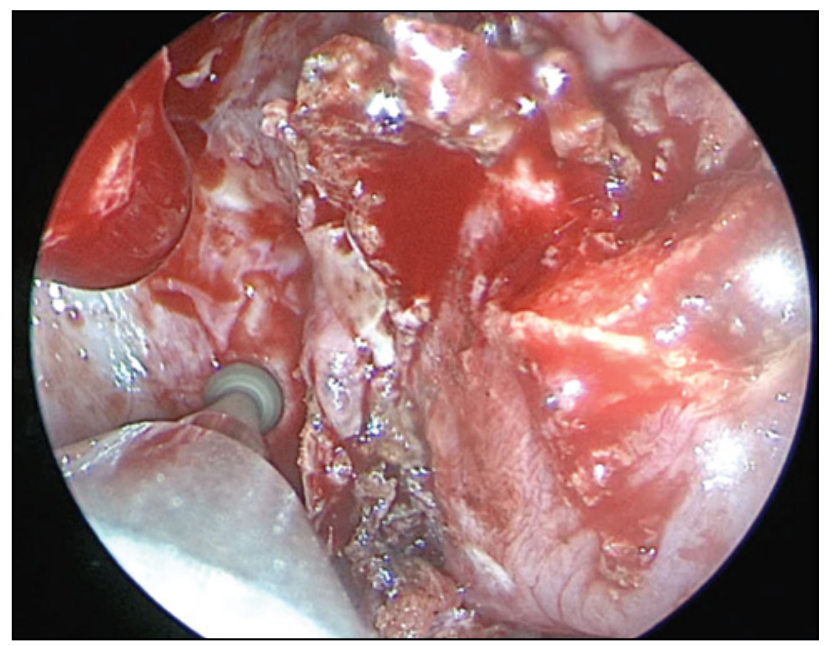

Figure 11 Removing the posterior bony wall of the maxillary sinus using a burr to gain access to the pterygopalatine fossa. 


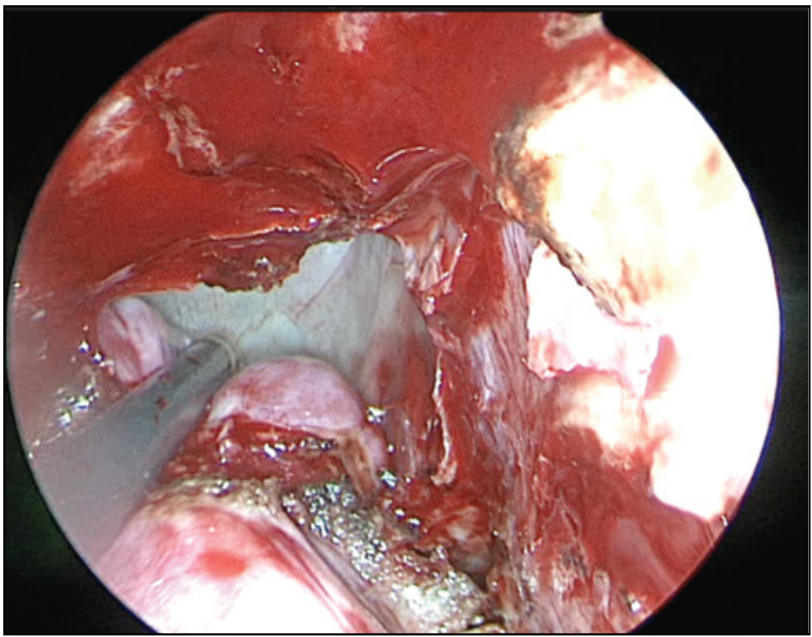

Figure 12 Intraoperative view of the superior-most aspect of the JNA inside the sphenoid sinus.

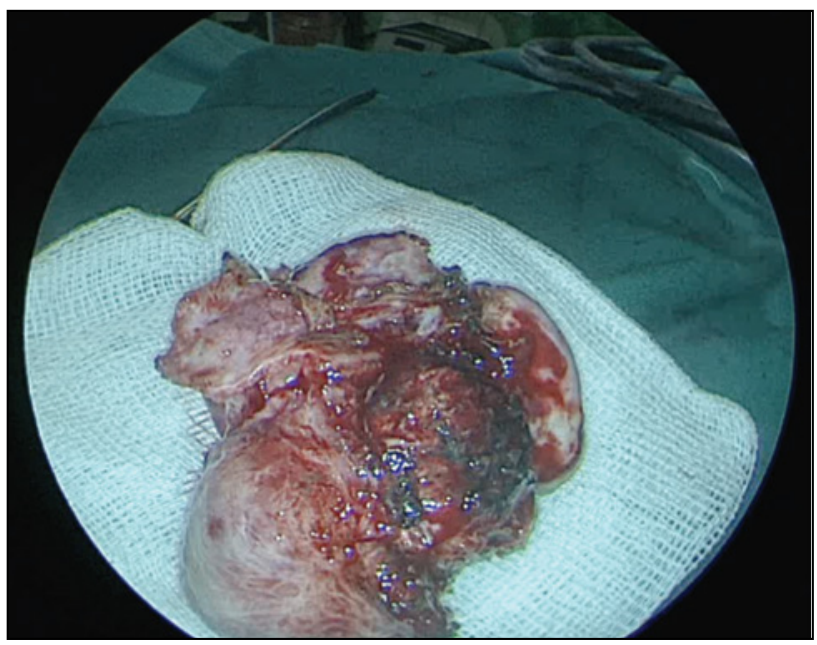

Figure 14 Gross en-bloc JNA specimen.

One patient required transfusion during the procedure due to significant blood loss, but no other morbidity was present. The other cases had mostly clear field dissection except for moderate and manageable bleeding around the vidian canal. Absorbable haemostatic pads were applied where minor bleeding persisted at the end of surgery. The average hospital stay was 5 days, ranging from 3 to 9 days (not including angiography and embolization that were performed in another clinic).

\section{CONCLUSIONS}

1. JNA should be included in the differential diagnosis of an adolescent male presenting with nasal obstruction and epistaxis.

2. Nasal endoscopy and thorough inspection of CT or MR imaging are sufficient to form a preliminary diagnosis and advise surgery.

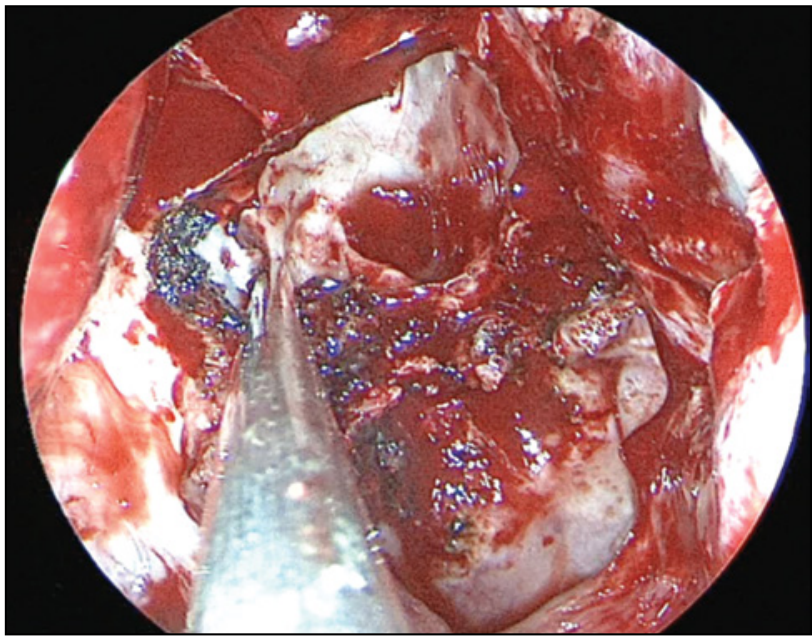

Figure 13 View at the end of surgery: the remaining cavity after JNA removal including the rhinopharynx, a wide opened right sphenoid sinus, right maxillary sinus, resected posterior third of the nasal septum.

3. Timely diagnosis greatly reduces surgical difficulty and possible complications.

4. Endoscopic surgery is a safe and effective approach to selected cases of juvenile nasopharyngeal angiofibroma.

Conflict of interest: The authors have no conflict of interest.

Contribution of authors: All authors have equally contributed to this work.

\section{REFERENCES}

1. Flint P, Haughey B, Lund V, Niparko J, Robbins K, et al. Cummings Otolaryngology: Head and Neck Surgery. 6th Edition. Saunders; 2014.

2. Tewfik TL, Al Garni MA. Juvenile Nasopharyngeal Angiofibroma Treatment \& Management. Medscape. Available from: https://emedicine.medscape.com/article/872580-treatment. [Accessed 8th January 2018].

3. Stokes SM, Castle JT. Nasopharyngeal angiofibroma of the nasal cavity. Head Neck Pathol. 2010;4(3):210-3. DOI: 10.1007/s12105-010-0181-7.

4. Zhang M, Sun X, Yu H, Hu L, Wang D. Biological distinctions between juvenile nasopharyngeal angiofibroma and vascular malformation: an immunohistochemical study. Acta Histochem. 2011;113(6):626-30. DOI: 10.1016/j.acthis.2010.07.003. Epub 2010 Aug 4.

5. Liang J, Yi Z, Liang P. The nature of juvenile nasopharyngeal angiofibroma. Otolaryngol Head Neck Surg. 2000;123(4):475-81.

6. Makhasana JAS, Kulkami MA, Vaze S, Shroff AS. Juvenile nasopharyngeal angiofibroma. J Oral Maxillofac Pathol. 2016;20(2):330. DOI: 10.4103/0973-029X.185908.

7. Schick B, Plinkert PK, Prescher A. Aetiology of Angiofibromas: Reflection on their Specific Vascular Component. Laryngorhinootologie 2002;81 (4):280-4.

8. Hwang HC, Mills SE, Patterson K, Gown AM. Expression of androgen receptors in nasopharyngeal angiofibroma: an immunohistochemical study of 24 cases. Mod Pathol. 1998;11(11):1122-6.

9. Shikani AH, Richtsmeier WJ. Juvenile nasopharyngeal angiofibroma 
tumor models. Failure of androgens to stimulate growth in nude mice and in vitro. Arch Otolaryngol Head Neck Surg. 1992;118(3):256-9.

10. Pernick N. Nasopharyngeal angiofibroma. Pathology Outlines. Available from: http://www.pathologyoutlines.com/topic/nasalangiofibroma. html. [Accessed 8th January 2018].

11. Liu L, Wang R, Huang D, Han D, Ferguson EJ, Shi H, et al. Analysis of intra-operative bleeding and recurrence of juvenile nasopharyngeal angiofibromas. Clin Otolaryngol Allied Sci. 2002;27(6):536-40.

12. Klatt EC. Robbins and Cotran Atlas of Pathology. 1st Edition. Elsevier Saunders; 2006, p.144.

13. Thurston M, Gaillard F. Juvenile nasopharyngeal angiofibroma. Radiopaedia. Available from: https://radiopaedia.org/articles/juvenilenasopharyngeal-angiofibroma. [Accessed 8th January 2018].

14. Ikubor JE, Okolugbo NE, Okhakhu AL. Radiological features of juvenile nasopharyngeal angiofibroma. J West Afr Coll Surg. 2013;3(4):84-91.

15. Mishra S, Praveena NM, Panigrahi RG, Gupta YM. Imaging in the diagnosis of juvenile nasopharyngeal angiofibroma. J Clin Imaging Sci. 2013;3(Suppl 1):1. DOI: 10.4103/2156-7514.109469.

16. Alimli AG, Ucar M, Oztunali C, Akkan K, Boyunaga O, Damar C, et al. Juvenile nasopharyngeal angiofibroma: magnetic resonance imaging findings. Journal of the Belgian Society of Radiology. 2016;100(1):63. DOI: http://doi.org/10.5334/jbr-btr.1090.

17. Som PM, Curtin HD. Head and Neck Imaging, Volume 1 und. Mosby; 2003.

18. Wu AW, Mowry SE, Vinuela F, Abemayor E, Wang MB. Bilateral vascular supply in juvenile nasopharyngeal angiofibromas. Laryngoscope. 2011;121 (3):639-43. DOI: 10.1002/lary.21337. Epub 2010 Oct 26.

19. Moulin G, Chagnaud C, Gras R, Gueguen E, Dessi P, Gaubert JY, et al. Juvenile nasopharyngeal angiofibroma: comparison of blood loss during removal in embolized group versus nonembolized group. Cardiovasc Intervent Radiol. 1995;18(3):158-61.

20. Petruson K, Rodriguez - Catarino M, Petruson B, Finizia C. Iuvenile nasopharyngeal angiofibroma: long-term results in preoperative embolized and non-embolized patients. Acta Otolaryngol. 2002;122(1):96-100.

21. McCombe A, Lund VJ, Howard DJ. Recurrence in juvenile angiofibroma. Rhinology. 1990;28(2):97-102.

22. Martins MB, de Lima FV, Mendonca CA, de Jesus EP, Santos AC, Barreto VM, et al. Nasopharyngeal angiofibroma: Our experience and literature review. Int Arch Otorhinolaryngol. 2013;17(1):14-9. DOI: 10.7162/ S1809-97772013000100003.

23. Elhammady MS, Johnson JN, Peterson EC, Aziz-Sultan MA. Preoperative embolization of juvenile nasopharyngeal angiofibromas: transarterial versus direct tumoral puncture. World Neurosurg. 2011;76(3-4):328-34; discussion 263-5. DOI: 10.1016/j.wneu.2010.11.011.
24. Budu V, Mogoanta CA, Fanuta B, Bulescu I. The anatomical relations of the sphenoid sinus and their implications in sphenoid endoscopic surgery. Rom J Morphol Embryol. 2013;54(1):13-6.

25. Andrews JC, Fisch U, Valavanis A, Aeppli U, Makek MS. The surgical management of extensive nasopharyngeal angiofibromas with the infratemporal fossa approach. Laryngoscope. 1989;99(4):429-37.

26. Radkowski D, McGill T, Healy GB, Ohims L, Jones DT. Angiofibroma. Changes in staging and treatment. Arch Otolaryngol Head Neck Surg. 1996;122(2): 122-9.

27. Budu V, Bulescu I, Mogoanta CA. Particular aspects in endoscopic surgery for juvenile nasopharyngeal angiofibromas. Case reports and review of literature. Rom J Morphol Embryol. 2013;54(3):867-870.

28. Godoy MD, Bezerra TF, Pinna FdeR, Voegels RL. Complications in the endoscopic and endoscopic-assisted treatment of juvenile nasopharyngeal angiofibroma with intracranial extension. Braz J Otorhinolaryngol. 2014;80(2):120-5.

29. Oliveira JA, Tavares MG, Aguiar CV, Azevedo JF, Sousa JR, Almeida PC, et al. Comparison between endoscopic and open surgery in 37 patients with nasopharyngeal angiofibroma. Braz J Otorhinolaryngol. 2012;78(1):75-80.

30. Ardehali MM, Samimi SH, Bakhshaee M. An effective technique for endoscopic resection of advanced stage angiofibroma. Iran J Otorhinolaryngol. 2014;26(74):25-30.

31. Zimmermann E, Selonke I, Gavazzoni FB, Pereira RG, Machado, Tanamati TK, et al. Endoscopic surgery of nasopharyngeal angiofibroma. Int Arch Otorhinolaryngol. 2010;14(2):206-11. DOI: 10.7162/S180948722010000200010 .

32. McAfee WJ, Morris CG, Amdur RJ, Werning JW, Mendenhall WM. Definitive radiotherapy for juvenile nasopharyngeal angiofibroma. Am J Clin Oncol. 2006;29(2):168-70.

33. Roche PH, Paris J, Regis J, Moulin G, Zanaret M, Thomassin JM, et al. Management of invasive juvenile nasopharyngeal angiofibromas: the role of a multimodality approach. Neurosurgery. 2007;61(4):768-77; discussion 777 .

34. Park CK, Kim DG, Paek SH, Chung HT, Jung HW. Recurrent juvenile nasopharyngeal angiofibroma treated with gamma knife surgery. J Korean Med Sci. 2006;21(4):773-7.

35. Tosun F, Onerci M, Durmaz A, Ugurel S. Spontaneous involution of nasopharyngeal angiofibroma. J Craniofac Surg. 2008;19(6):1686-9. DOI: 10.1097/SCS.0b013e3181897222.

36. Weprin LS, Siemers PT. Spontaneous regression of juvenile nasopharyngeal angiofibroma. Arch Otolaryngol Head Neck Surg. 1991;117(7):796-9. 